\title{
Shellfish farm-induced changes to tidal circulation in an embayment, and implications for seston depletion
}

\author{
David R. Plew* \\ National Institute for Water and Atmospheric Research (NIWA), Hydrodynamics Group, PO Box 8602, Christchurch, New Zealand
}

\begin{abstract}
Marine farm structures cause drag, which can affect currents over large areas. This study uses numerical modelling to consider the effect of long-line mussel farms on tidal currents within embayments. The modelling illustrates how currents can be altered over most of a bay by farms that occupy a relatively small (10\%) proportion of the bay. The effect of several small farms located around a bay perimeter are compared to that of a large farm of equivalent area placed in different parts of the bay. While results show that current speeds are reduced in most places, particularly inside farms, different farm locations may increase velocities in some parts of a bay. Changes in currents caused by farm drag have an important influence on potential seston depletion, which is simulated using a tracer released from farmed areas. A simple decay rate is used to simulate plankton regrowth and seston replenishment. The depth-averaged modelling is based on 2 neighbouring bays: Port Ligar and Waihinau Bay, in the Pelorus Sound, New Zealand. Existing mussel farms in these bays occupy $10 \%$ of the area of each bay and are located near $(<400 \mathrm{~m})$ to shore, forming a broken ribbon around the perimeter of each bay. Existing farms reduce mean current speeds by an average of $7 \%$ in Port Ligar and $3 \%$ in Waihinau Bay. The difference is attributed to the different aspect ratios of the 2 bays. Neglecting farm drag results in over-predicting dispersal and under-predicting the degree of depletion within farms. At both sites, seston depletion is least likely to occur in farms placed in the outer parts of bays where currents are faster.
\end{abstract}

KEY WORDS: Aquaculture · Mussel farm · Long-lines · Drag · Currents · Hydrodynamic modelling

\section{INTRODUCTION}

Many forms of aquaculture use structures suspended in the water, such as cages and nets for fish, and rafts, long-lines and racks for shellfish. The drag from such structures reduces water velocities within farmed areas (Plew et al. 2005, Strohmeier et al. 2005, Aure et al. 2007). Currents, along with waves and mixing, are key agents for transport of nutrients and wastes (Stevens et al. 2008). For filter feeders such as shellfish, lower current speeds within farmed areas reduce the supply of seston and increase the risk of seston depletion, both of which may limit production (Hawkins et al. 1999, Pilditch et al. 2001, Strohmeier et al. 2005, Aure et al. 2007); and reduce the dispersal of waste products (Hartstein \& Stevens 2005, Weise et al. 2009).
Assessments of the impact of marine farms on carrying capacity should therefore account for the reduction in water speeds caused by the farms (Boyd \& Heasman 1998, Aure et al. 2007).

It can be difficult to accurately measure the effect of existing marine farms on currents. Ideally, field measurements would need to be taken with and without the farm being present; however, opportunities to take such measurements are limited. Furthermore, for sites close to shore it can be difficult to separate the effects of the farm from those of shoreline topography. Numerical modelling provides an alternative approach where farm impacts can be predicted, different farm configurations tested, and effects potentially minimised. Numerical modelling has shown that there can be significant effects on current speeds where the 
aquaculture covers a large proportion of a bay (Grant \& Bacher 2001). However, in New Zealand coastal waters, farms that occupy a large proportion of a bay are seldom permitted; instead inshore farming is generally confined to narrow regions near the shore. While individual marine farms may be small ( 1 hectare), several small farms can collectively form a ribbon of farms along the shoreline of a bay. It is not clear what the collective effect of these small marine farms is on currents and circulation within bays, or how the collective effect of several small farms compares to that of a single large farm covering the same total area.

Most of the area used for marine farming in New Zealand is presently devoted to suspended culture of green-lipped mussel Perna canaliculus. Mussels are grown on ropes looping from a row of surface floats. The depth to which the loops extend varies among operators, but loops have been observed to extend nearly to the bed in $35 \mathrm{~m}$ of water depth at some sites. In the present study, the rows of floats and crop rope are called 'long-lines'. Each long-line is typically 100 to $120 \mathrm{~m}$ in length, supporting around $5 \mathrm{~km}$ of crop rope. In small near-shore farms, rows of long-lines are aligned parallel to the shore, with 8 to 12 long-lines spaced at 10 to $20 \mathrm{~m}$. Measurements have shown that where mussel crop ropes do not reach the bed, current velocities beneath long-lines are increased (Gibbs et al. 1991, Boyd \& Heasman 1998, Plew et al. 2006); an effect that should be accounted for when considering deposition beneath marine farms. However, less evidence is available regarding the spatial scales over which the physical effects of marine farms extend.

The purpose of the present study was to investigate the cumulative effect of several small mussel farms on bay-scale currents and how farm-induced changes to currents affect the degree and extent of seston depletion. Numerical modelling was used to compare currents with and without the drag from mussel farms, and potential seston depletion was simulated using a tracer released from farmed areas. Modelling was also conducted to compare the effects of several small farms to a single large farm. While the primary aim of this study was to highlight the influence and importance of farm drag on bay-scale currents, the modelling was based on present mussel farm locations in Port Ligar and Waihinau Bay, New Zealand in order to be representative of a real aquaculture environment.

\section{METHODS}

Study site. Waihinau Bay and Port Ligar are located near the entrance of Pelorus Sound (South Island, New Zealand, Fig. 1). Port Ligar is approx. $4 \mathrm{~km}$ long and $1.5 \mathrm{~km}$ wide. The narrowest point is about two-thirds into the bay before widening at the head of the bay. The bay has an area of $8.3 \times 10^{6} \mathrm{~m}^{2}$ and an average depth of $30 \mathrm{~m}$. Waihinau Bay is nearly circular in shape, approx. $1.6 \mathrm{~km}$ in diameter, with an area of $2.2 \times 10^{6} \mathrm{~m}^{2}$ and an average depth of $26 \mathrm{~m}$. The 2 bays are typical of inshore farming in New Zealand, having several small marine farms located around the bay perimeter. There are 18 farms in Port Ligar and 6 in Waihinau Bay, although 2 farms near the entrance of Waihinau Bay are also included in the simulations. The farms vary in area and in number of long-lines. In Port Ligar the 18 farms cover a total area of $878000 \mathrm{~m}^{2}$ with approx. 220 long-lines. The 6 farms within Waihinau Bay occupy $210000 \mathrm{~m}^{2}$, with approx. 60 long-lines, and the 2 additional farms immediately south of Waihinau Bay total $82000 \mathrm{~m}^{2}$, with approx. 20 long-lines Sontek (San Diego) $500 \mathrm{kHz}$ acoustic Doppler profiler (ADP) current meters

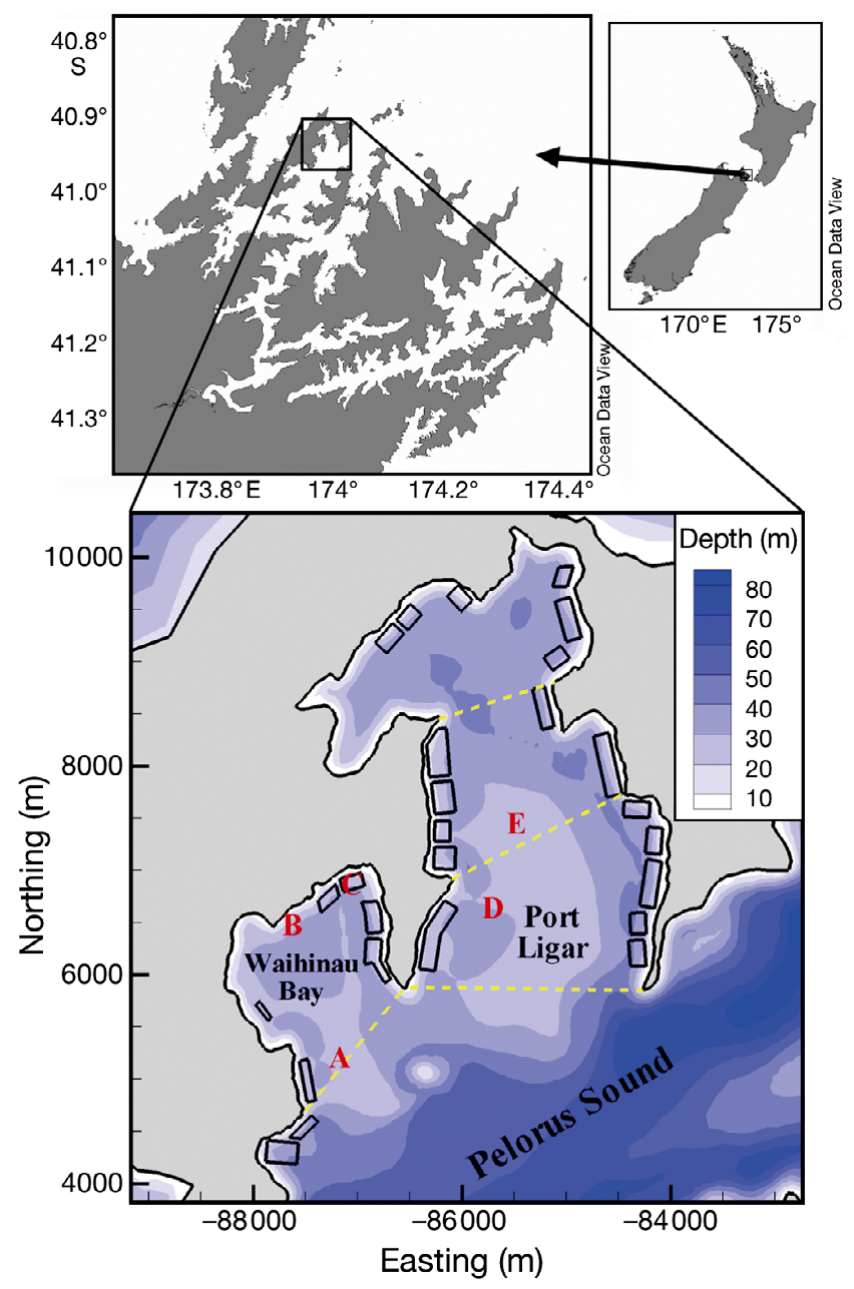

Fig. 1. Location and bathymetry of study site Port Ligar and Waihinau Bay, Pelorus Sound, New Zealand. In lower picture: boxes $=$ locations of mussel farms; letters $=$ mooring of current meters; dashed lines = boundaries of Waihinau Bay and Port Ligar, and where Port Ligar has been divided into inner, middle and outer regions for comparison of predicted water speeds 
were moored at the 5 locations shown in Fig. 1. The current meters were placed on the sea floor, and velocities averaged over a $120 \mathrm{~s}$ period every $600 \mathrm{~s}$ at $1 \mathrm{~m}$ vertical intervals. Velocity data were depth-averaged during post-processing.

Numerical model. The hydrodynamic model RiCOM (Walters 2005) was used to conduct depth-averaged simulations of tidal currents. This finite-element model uses an unstructured grid with triangular elements, semiimplicit time-stepping and a semi-Lagrangian advection scheme (Walters et al. 2007). Further details and descriptions of the numerical schemes used in the model are described elsewhere (Walters \& Casulli 1998, Walters \& Plew 2008). The model grid used for the present study extends a considerable distance away from the study site (the domain covers $\sim 490 \times 210 \mathrm{~km}$ ) in order to produce realistic flows through Cook Strait which, in turn, influence currents in Pelorus Sound. This also allows the use of boundary conditions found to produce accurate currents through Cook Strait (Walters et al. 2010) without resorting to grid nesting. Grid resolution varies from $\sim 5-10 \mathrm{~km}$ at the off-shore boundaries, becoming progressively finer down to $\sim 200 \mathrm{~m}$ in most of Pelorus Sound, and 25-50 m in Port Ligar and Waihinau Bay. The model grid contained 32013 nodes and 60035 triangular elements. Simulations were started with an initially flat sea surface with zero velocities everywhere. Tidal amplitudes were ramped up linearly over $12.42 \mathrm{~h}$ (1 M2 tidal cycle), and the simulations run for $12 \mathrm{M} 2$ tidal cycles $(149 \mathrm{~h})$ simulation time before output was recorded to avoid start-up transient effects.

Model validation was conducted by comparing velocities predicted by the model with depth-averaged velocities from current meters (Sontek acoustic Doppler current profilers) at the 5 locations shown in Fig. 1. Sites A, B, and C were located in Waihinau Bay, while sites D and E were located within Port Ligar. Site C was inside a mussel farm, while all other instruments were outside farms. The validation simulation was conducted using 4 semi-diurnal (M2, S2, N2, K2) and 3 diurnal (K1, O1, P1) tidal constituents, applied by specifying the water elevation at the open boundaries. The M2, or principal lunar semi-diurnal tidal constituent, is the largest in the New Zealand region, followed by the principal solar semi-diurnal constituent (S2) which together account for much of the modulation in tidal range between neap and spring tides around New Zealand (Heath 1985).

In all other simulations used to assess the effect of the farms on currents and dispersal, only the M2 tidal constituent was applied in order to study the effect of farms during average tidal ranges. The M2 tidal constituent has an amplitude of $0.75 \mathrm{~m}$ in Port Ligar. The typical spring-neap range in Port Ligar is 0.4 to $1.1 \mathrm{~m}$, and using only the M2 component in simulations gives a reasonable approximation of average tidal amplitude. Wind forcing, barometric pressure and baroclinic effects were not included.

Farm drag parameterisation. Shear stress $(\tau)$ from bottom friction is applied in the model through

$$
\tau=\rho C_{\mathrm{b}} U|U|
$$

where $\rho$ is the water density, $C_{\mathrm{b}}$ a friction coefficient for the bed and $U$ the depth-averaged velocity. The drag from the marine farms is included by modifying the friction coefficient to account for drag from the farm structures as well as the increased bed shear stress resulting from accelerated flow beneath the farms. The derivation of the modified friction coefficient, along with a comparison with laboratory data, are described by Plew (2011). In brief, farms are treated as porous obstacles in a similar manner to vegetation canopies. The hanging crop ropes collectively form a canopy extending downward from the water surface, with a gap between the canopy and the seafloor. Flow inside the farmed areas is treated as 2 layers: within the farm canopy (the proportion of the water depth occupied by the mussel crop) and beneath the farm canopy. Drag from the farm canopy acts in the upper layer while bottom friction is applied to the lower layer. The shear between the 2 layers is parameterised as a mixing layer. The bed friction coefficient in Eq. (1) is replaced with a total friction coefficient $C_{\mathrm{t}}$ in farmed areas,

$$
C_{\mathrm{t}}=A h u_{\mathrm{c}}^{2}+C_{\mathrm{b}} u_{\mathrm{b}}^{2}
$$

The farm drag is represented by $A=C_{\mathrm{d}} a H / 2$ where $C_{\mathrm{d}}$ is the drag coefficient of a single mussel dropper (Plew et al. 2009), a the projected area of mussel droppers per unit volume (a measure of both the farm stocking density and mussel size), and $H$ the water depth. $u_{\mathrm{c}}=U_{\mathrm{C}} / U$ is the velocity within the farm canopy non-dimensionalised by the depth-averaged velocity, $u_{\mathrm{b}}=U_{\mathrm{b}} / U$ the non-dimensional velocity beneath the farm canopy, and $h$ is the proportion of the water depth covered by the canopy (canopy thickness divided by water depth). The friction coefficient $C_{\mathrm{t}}$ is obtained by first calculating the non-dimensional velocities within and beneath the canopy. The velocity within the farm canopy is

$$
u_{\mathrm{c}}=\frac{-\alpha^{2}-C_{\mathrm{b}} h^{2}+(1-h) \sqrt{A h(1-h)\left(\alpha^{2}+C_{\mathrm{b}} h\right)-\alpha^{2} C_{\mathrm{b}} h}}{A h(1-h)^{3}-\alpha^{2}-C_{\mathrm{b}} h^{3}}
$$

The velocity beneath the farm is

$$
u_{\mathrm{b}}=\frac{1-u_{\mathrm{c}} h}{1-h}
$$

The mussel farms were assumed to be typical of New Zealand configurations with $5 \mathrm{~km}$ of crop rope per long-line. Crop ropes were assumed to extend to $80 \%$ of the water depth, and to have an average diameter of $0.16 \mathrm{~m}$ including the mussels. A drag coefficient of 
$C_{\mathrm{d}}=1.0$ was used for the crop ropes (Plew et al. 2009). $\alpha=0.2$ is a parameter relating the shear in the mixing layer to the difference in velocity within and beneath the farm canopy (Plew 2011). A bed friction coefficient of $C_{\mathrm{b}}=0.0025$ was applied throughout the domain. Based on these assumptions, the following were derived: $A=0.124, C_{\mathrm{t}}=0.084, u_{\mathrm{c}}=0.89$, and $u_{\mathrm{b}}=1.43$.

This parameterisation of farm drag neglects any influence of stratification on the diversion of flow through or around the farms (Plew et al. 2006). However, the 2 bays are generally well-mixed compared to the inner Pelorus Sound, and the barotropic approximation is consistent with the use of a depth-averaged model.

Dispersal modelling. Mussels consume seston, leading to a decrease in seston concentrations. Farminduced changes in currents will effect how sestondepleted water is transported and mixed with surrounding fluid. The rate of seston consumption will depend on the crop size and stocking density, and may also be influenced by seston concentrations (Winter 1973, Riisgard 1991, Riisgard et al. 2003, Maire et al. 2007, Saurel et al. 2007). Phytoplankton (a component of seston) growth is controlled by a great number of factors including species, nutrient availability, light, and temperature (Goldman 1986, Cloern et al. 1995). A comprehensive model of seston depletion would need to include phytoplankton dynamics, along with mussel feeding behaviour and knowledge of ambient nutrient and seston concentrations. The purpose of the present study is not to model phytoplankton dynamics, but rather to indicate the likely spatial extent of the effects of long-line mussel farms. Therefore, in this study, seston depletion is modelled in a simple manner using a tracer released from farmed areas. The concentration of the tracer represents the amount of seston removed from the water, and indicates the degree of seston depletion caused by consumption by the mussels.

The tracer was continuously added at a constant rate of $1 \mathrm{~g} \mathrm{~m}^{-3} \mathrm{~h}^{-1}$ (the results can be scaled if the mass release rate or seston consumption rate is known) and assigned a decay rate $k\left(\mathrm{~d}^{-1}\right)$ to approximate the effects of seston replenishment by re-growth. Decay coefficients of $k=0.1,0.3$, and $1.0 \mathrm{~d}^{-1}$ are used to simulate a range from slow re-growth/decay, moderate regrowth/decay, and rapid re-growth/decay (Kiørboe 1989). At each time step, the tracer concentration $(S)$ in each grid element is adjusted as $S_{t}=S_{t-1}-k S_{t-1} \Delta t$ where $\Delta t$ is the time step and $S_{t}$ the tracer concentration at time $t$.

The tracer is advected by the flow field and horizontal diffusion modelled through $K_{\mathrm{H}}$, the horizontal eddy diffusivity. Stevens (2010) reports $K_{\mathrm{H}}$ ranging from 0.1 to $5.0 \mathrm{~m}^{2} \mathrm{~s}^{-1}$ in Crail Bay, located further into Pelorus Sound. These diffusivities represent mixing from both large and small turbulence scales. A constant diffusiv- ity of $K_{\mathrm{H}}=0.1 \mathrm{~m}^{2} \mathrm{~s}^{-1}$ was assumed in our simulations. While this is a low value for bays of this size (Okubo 1971), it is based on the grid resolution rather than the size of the bay on the basis that dispersion from shear over length-scales greater than the grid resolution is resolved by the flow field.

The total mass $M$ of a continuously released nonconservative tracer is

$$
M=\frac{R}{k}\left(1-\mathrm{e}^{-k t}\right)
$$

where $R$ is the rate of tracer mass addition, summed across all the farms $\left(\mathrm{kg} \mathrm{d}^{-1}\right)$. In the absence of advection or diffusion, the total mass of tracer would asymptotically reach a steady state maximum of $M=R / k$. Simulations comparing tracer concentrations were conducted by first continuously releasing tracers until the total tracer mass reached $90 \%$ of the maximum, and then averaging tracer concentrations over a complete M2 tidal cycle $(12.42 \mathrm{~h})$. The time required to reach $90 \%$ of steady state tracer mass is $t=-\ln (0.1) / k$. Noting that tracer may be leaving the area of interest (Port Ligar and Waihinau Bay) during this period, steady state concentrations within the bays may be reached sooner.

While seston depletion is considered here, this approach could be applied to simulate dispersal of any other suspended or dissolved substance. More complex behaviour, such as swimming or sinking, could be added to simulate active tracers (Gillibrand \& Willis 2007), however only a passive, neutrally-buoyant, tracer is considered here.

\section{RESULTS}

\section{Comparison with current meter mooring}

The model generally showed good agreement with the current meters at sites in Waihinau Bay during periods of low wind speed (Fig. 2). The model, using 7 tidal constituents, accurately predicted the magnitude and timing of the highest velocities of each tidal cycle. The model reproduces the low speeds at meter site B and inside the farm at site C. However, the variability within each tidal cycle was less well resolved. Wind forcing, which was not included in the simulations, may have contributed to some of this variability. The model does not match as closely for current meters in Port Ligar (sites D and E). At site D the model slightly over-predicts the north-south component, and does not show the westerly drift between hours 100 to 175 , but the comparison improves after this time. At site $\mathrm{E}_{\text {, }}$ the model shows a larger east-west velocity component than observed. The model also predicts a net 

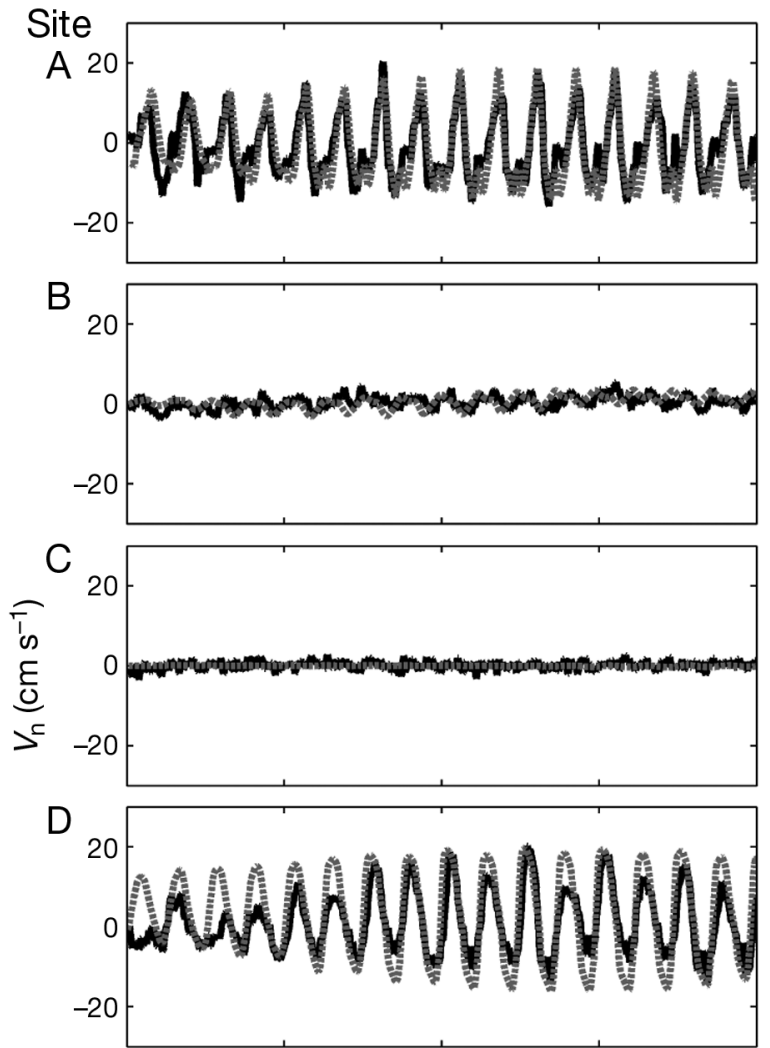

E

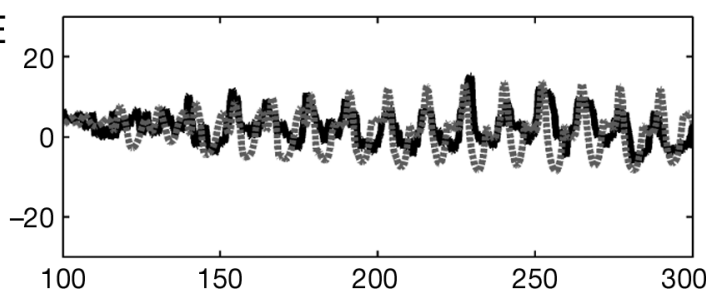

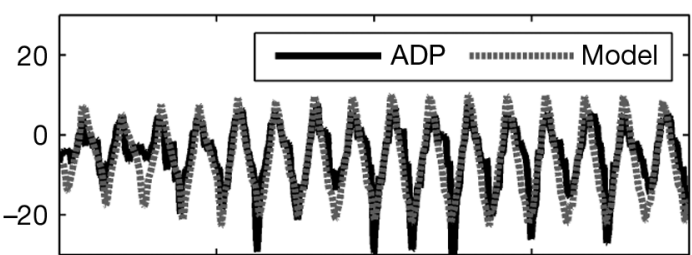
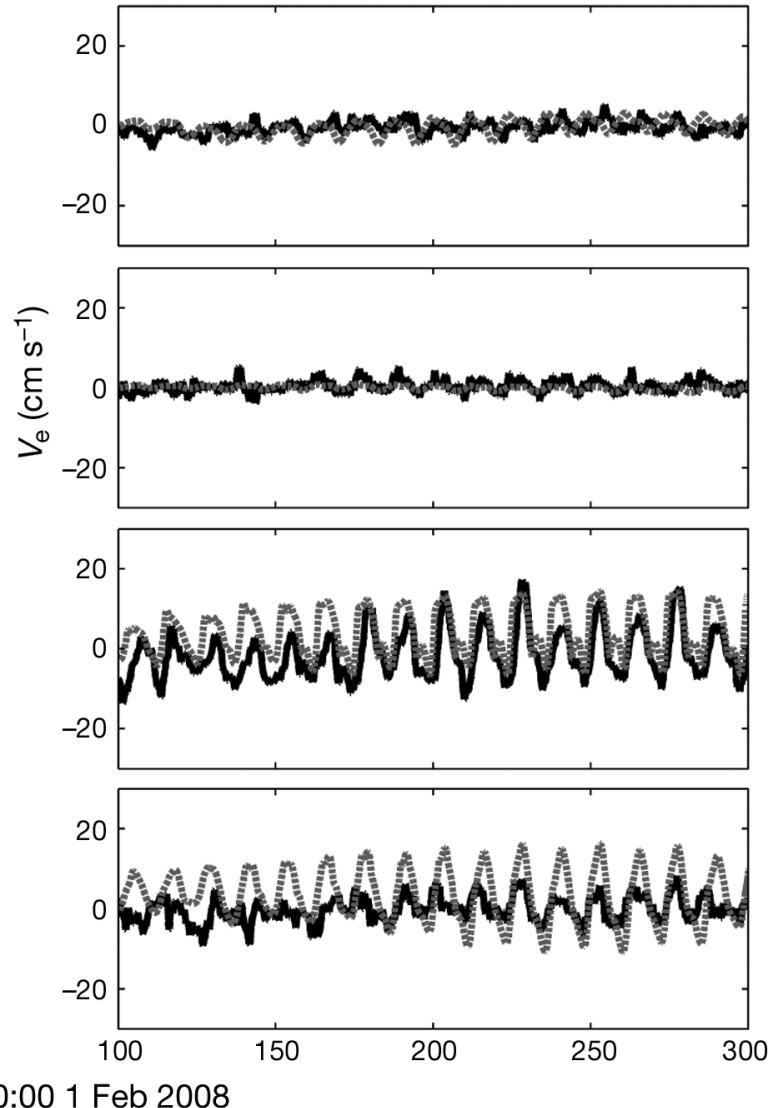

Fig. 2. Current meter data (Acoustic Doppler Profiler; ADP, SonTek) and model results in Waihinau Bay and Port Ligar, Feb 2008 for sites A to E. Graphs show the depth-averaged velocity components in the northern $\left(V_{\mathrm{n}}\right)$ and eastern $\left(V_{\mathrm{e}}\right)$ directions. Locations of the current meters are shown in Fig. 1

easterly drift between hours 100 and 175 that is not observed. Current meter $\mathrm{E}$ is in an area where the model indicates that vortices are strong (Fig. 3). The current meter data shows considerable subtidal variability, which is consistent with passing vortices that may be shed from the small headland that separates the mid and outer bay. The model illustrates that flow is highly variable where current meters $\mathrm{D}$ and $\mathrm{E}$ are located, and in particular, there is high shear from the tidal jet along the western shore of Port Ligar on rising tides. Small errors in the modelled trajectory of currents in this region would give large differences between simulated and measured currents. These errors could arise from small-scale bathymetric features influencing flow near current meters that are not resolved in the bathymetry data set, vertical shear, or numerical diffusion in high shear regions.

\section{Modelled tidal currents without farms}

The model predicts a complex flow field including features such as gyres induced by flow separation behind points either side of the bay entrances. Velocity vectors and vorticity at mid-rising and mid-falling tide are shown in Fig. 3. Major features of note are the strong clockwise rotating gyres at the south-east of each bay on the rising tide (Fig. 3a). These gyres are accompanied by weaker anti-clockwise rotating gyres further into each bay. These secondary gyres persist with anti-clockwise rotation on the falling tide (Fig. 3b). There is a southerly current along the southeastern edge of both bays over much of both rising and falling tides. Strongest currents occur near the southern (open) end of the bays. Maximum water speeds over an M2 tidal cycle generally increase from the 

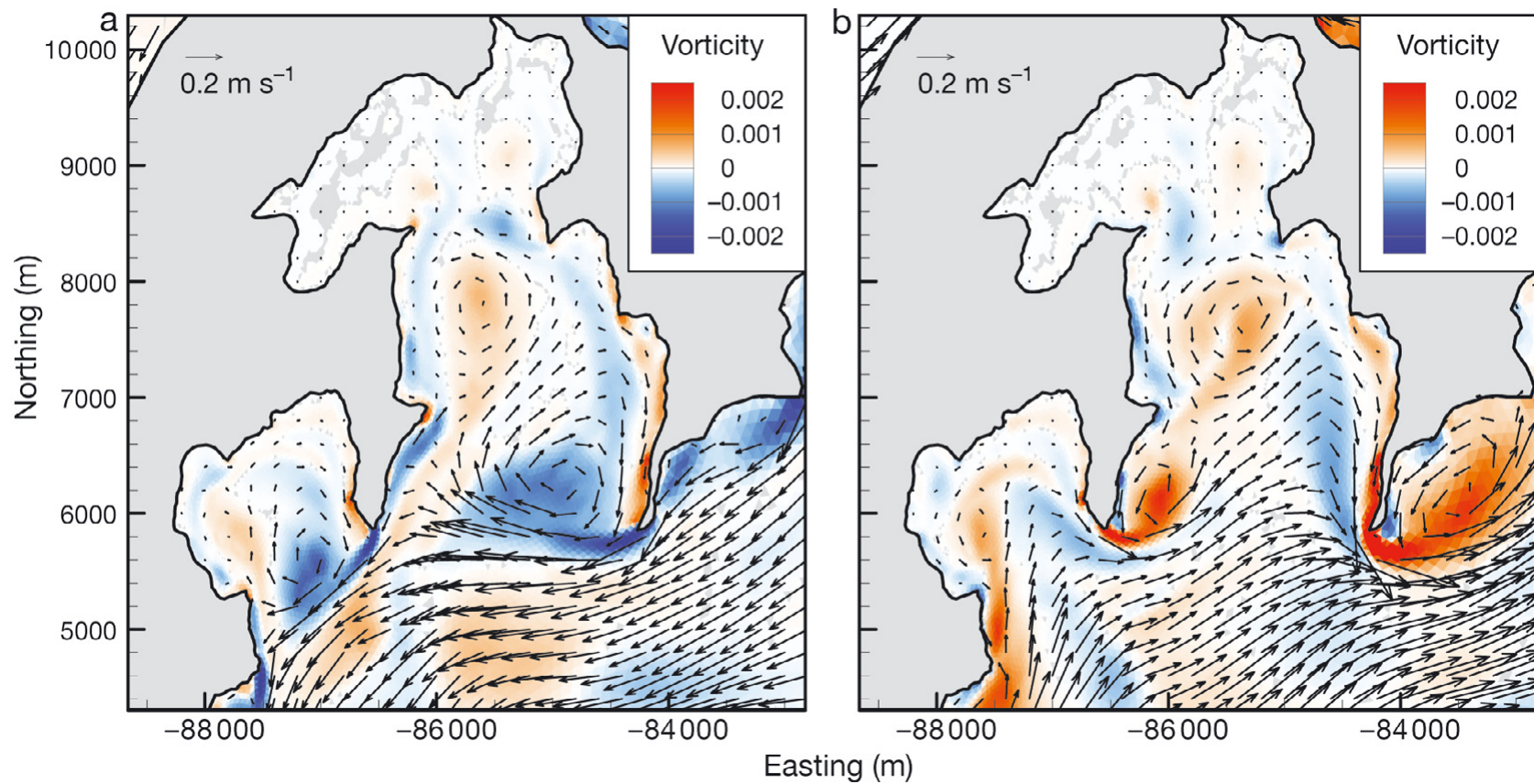

Fig. 3. Modelled velocity vectors at (a) mid-rising tide and (b) mid-falling tide (M2 component only) and vorticity. Velocity vectors have been interpolated on to a coarser $200 \times 200 \mathrm{~m}$ grid to improve clarity. On the rising tide, water flows into Pelorus Sound producing a clockwise rotating gyre in the south of Port Ligar, and a weaker counter-clockwise rotating gyre in the middle portion of the bay. On falling tides, separation occurs at the headland on the south-west bay entrance, and a counter clockwise circulation is maintained in the mid-bay

inner $\left(<5 \mathrm{~cm} \mathrm{~s}^{-1}\right)$ to the outer $\left(20-40 \mathrm{~cm} \mathrm{~s}^{-1}\right)$ portions of the bays, while mean (RMS) speed reaches $\sim 13 \mathrm{~cm} \mathrm{~s}^{-1}$ in the bay entrances (Fig. 4a). In the absence of farms, bay-averaged maximum water speeds are 10.8 and $8.3 \mathrm{~cm} \mathrm{~s}^{-1}$ in Port Ligar and Waihinau Bay, respectively. Mean water speeds are 5.3 and $4.2 \mathrm{~cm} \mathrm{~s}^{-1}$, respec- tively. Residual currents, calculated by averaging velocities over a tidal cycle, illustrate the persistence of the large gyres in Port Ligar, and the pattern of net inflow along the eastern sides and outflow along the western sides of both Waihinau Bay and Port Ligar (Fig. 5a).
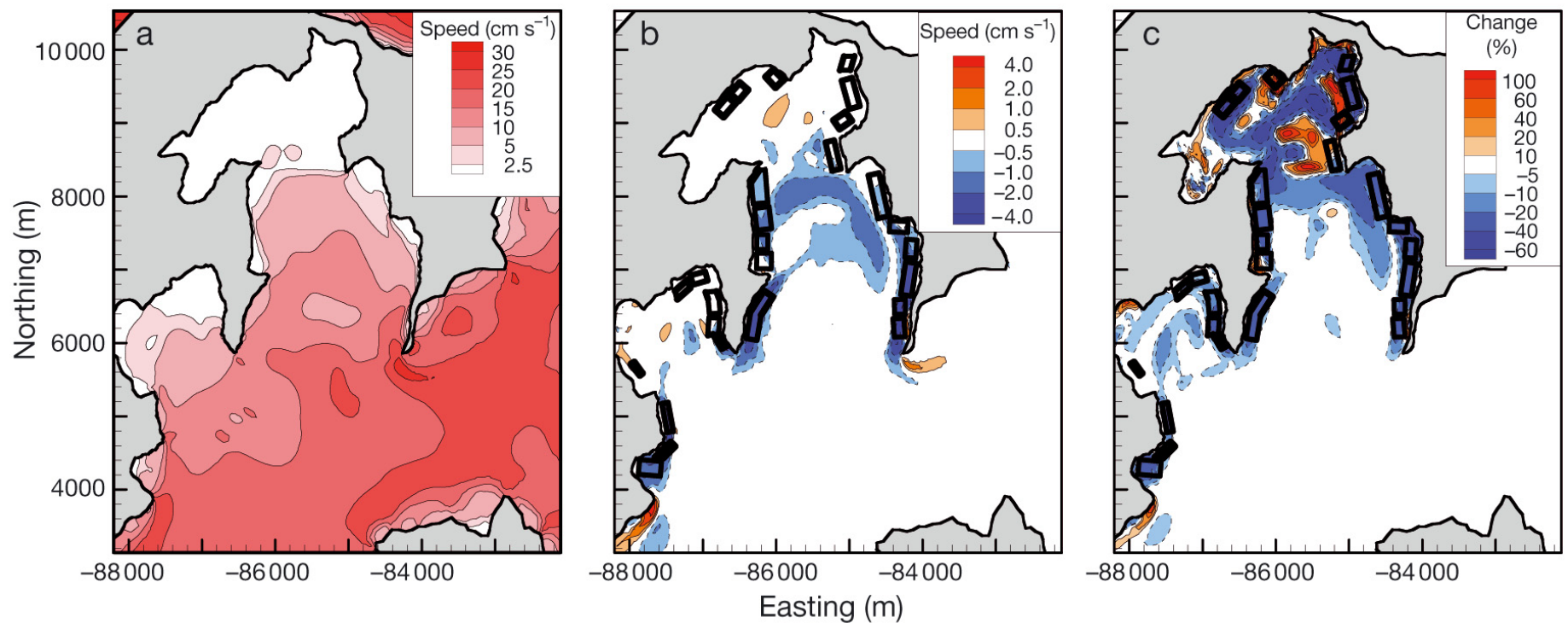

Fig. 4. (a) Modelled mean M2 current speeds with no farms, (b) difference in mean speeds and (c) \% change in mean speeds due to farm drag. Decreases in water speed are indicated with dashed contour lines. Boxes in $(\mathrm{b}, \mathrm{c})$ : farm positions 

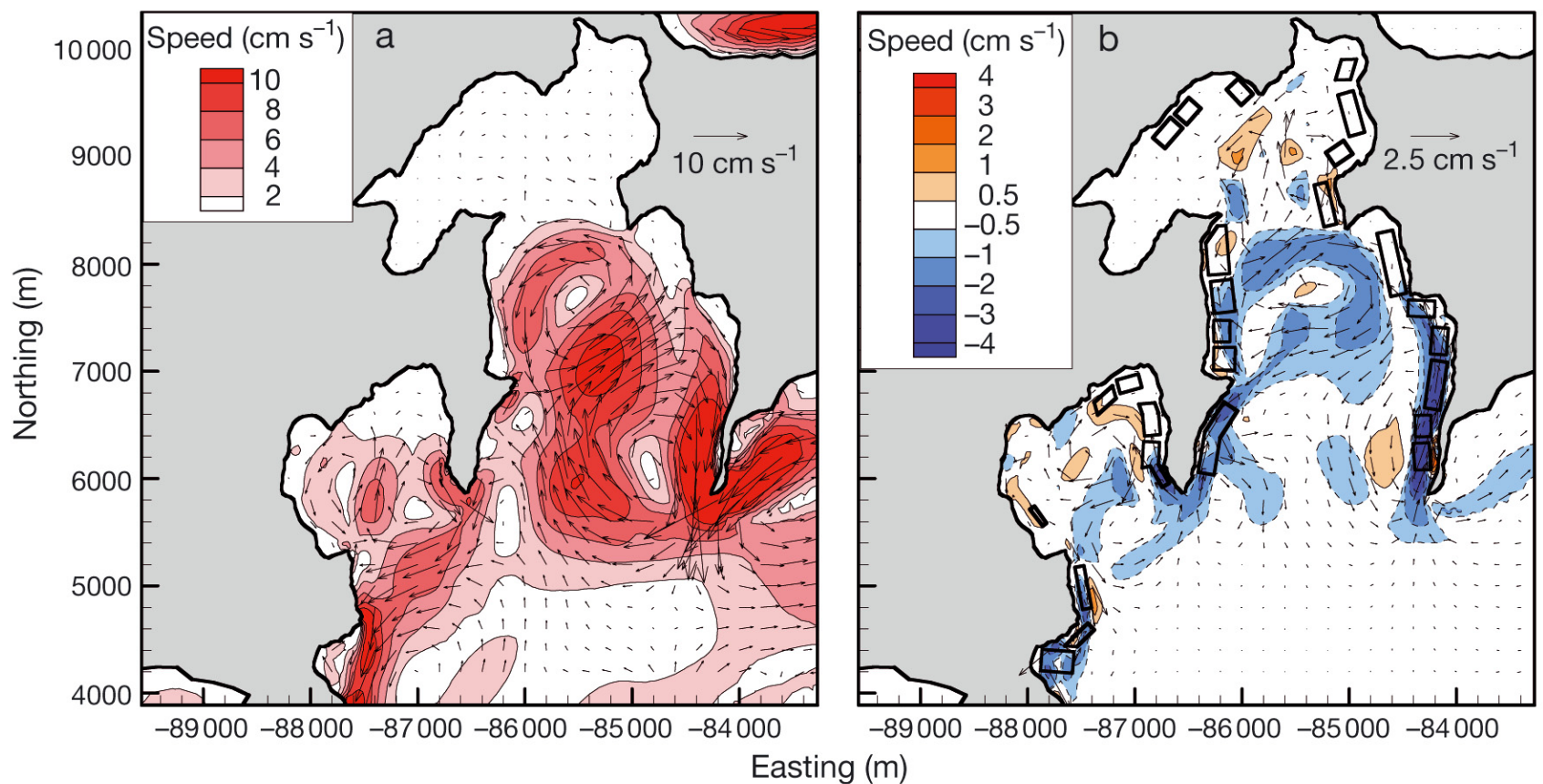

Fig. 5. (a) Residual current speeds with no farms, and (b) difference in residual speeds. Decreases in water speed are indicated with dashed contour lines. Boxes: farm positions

\section{Effect of marine farms on currents}

General flow patterns are similar when the marine farms are included in the simulations. Changes in water speed are greatest inside farms in areas where current speeds are high. Reductions in water speed clearly extend beyond farm boundaries (Fig. 4b). This is particularly evident in wake regions extending from the south-easternmost farm in Port Ligar. Relative changes in water speed are shown as \% changes in Fig. 4c. Reductions in water speeds of typically 25 to $45 \%$ occur inside most mussel farms, although there are some farms in the inner regions of both bays where mean water speed is increased. This increase in speed is due to diversion of flow by other mussel farms. The largest \% reduction in water speed occurs in the northeast of Port Ligar, where reductions in excess of $60 \%$ are predicted. However, there is also an area of increased mean water speed in the centre of inner Port Ligar of up to $160 \%$. Both of these areas of large change are outside farms. When averaged across the entire bay, mean water speeds are reduced by $7.3 \%$ in Port Ligar and $2.8 \%$ in Waihinau Bay, with similar reductions in maximum bay-averaged velocities. Simulations were also conducted that included all other farms within Pelorus Sound (605 farms), and including these farms results in a further $3 \%$ reduction in the bay-averaged water speeds within Port Ligar.

Residual tidal currents are decreased over much of Port Ligar and to a lesser extent Waihinau Bay, although there are small areas in each bay where the residual speed is increased. Reductions occur in most farms, and the largest changes are within farms along the south-eastern shore (Fig. 5b). However, the pattern of a clockwise residual in the outer bay and an anticlockwise residual in the middle of the bay are maintained.

Simulations were conducted using different farm drag to test the sensitivity of reductions in mean water speed to farm stocking density and crop size. The farm stocking density was represented through the projected area of crop rope per unit area (a) which is the product of the diameter of the crop rope (representing crop maturity) and the number of crop ropes per unit area. To aid comparison, the time-averaged speeds have been spatially averaged inside and outside the farms for Port Ligar and Waihinau Bay (Fig. 6). The graph shows speeds averaged over the full water depth, and as described previously, water speeds within the farm canopy will be $11 \%$ less than the depth-averaged value due to a diversion of flow beneath the farm. The depth-averaged drag coefficient within farmed areas is normalised by the bottom friction coefficient in Fig. 6. Increasing farm drag results in bigger reductions in the average speed, both inside and outside farmed areas, even though there are some farms in inner Port Ligar where mean speeds are increased. The relationship between farm drag and mean speed is not linear as the rate of change reduces as the drag becomes larger. Reductions in water speed 


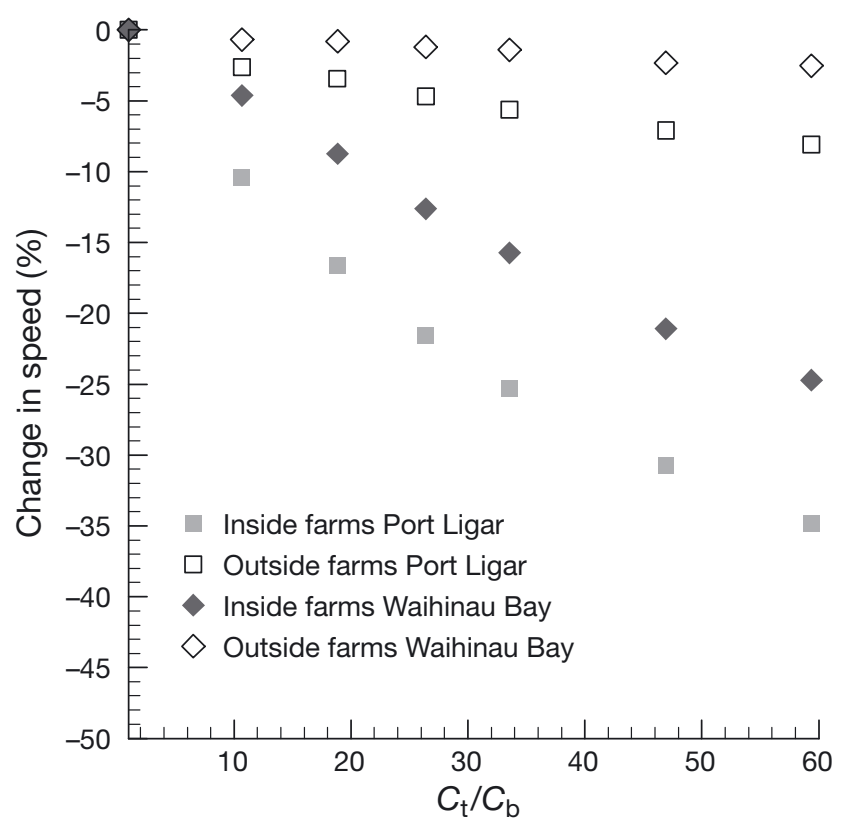

Fig. 6. Changes in depth-averaged mean current speeds within Port Ligar and Waihinau Bay as a function of the ratio of the drag coefficient in farmed areas $\left(C_{\mathrm{t}}\right)$ to the bed friction coefficient $\left(C_{\mathrm{b}}\right)$. A ratio of $C_{\mathrm{t}} / C_{\mathrm{b}}=34$ represents the standard farm drag in the present study. Note that the mean current speeds inside the farm canopies are $11 \%$ less than the depthaveraged speed due to a diversion of flow beneath the farm

are smaller in Waihinau Bay than in Port Ligar even though the portions of the bays occupied by mussel farms are similar (9.5 and $10.6 \%$ respectively). This is due to the different aspect ratios of the bays. Port Ligar is long and narrow and the farms along the perimeter of cause a greater restriction to flow into the bay than in the nearly circular Waihinau Bay. At the standard farm density $\left(C_{\mathrm{t}} / C_{\mathrm{b}}=34\right)$, the depth-averaged water speed within farms in Port Ligar is reduced by $25 \%$, which equates to a $33 \%$ reduction in speed within the canopy. Average reductions over the whole bay are $7 \%$ for Port Ligar and 3\% for Waihinau Bay.

\section{Alternative farm layouts}

Simulations were conducted to compare the effect of a single large farm covering the same total area as the existing farms in Port Ligar. In these simulations, only farms in Port Ligar are considered. Changes in mean current speed relative to a no-farm simulation are shown in Fig. 7, and changes averaged over each region of the bay are reported in Table 1. The reductions in water speed when only farms in Port Ligar are included (Fig. 7a) are different from those calculated from simulations that include farms in Waihinau Bay (Fig. 4c). This shows that the influence of farms in one bay can be felt in another. This is particularly evident in inner Port Ligar. However, speeds are low in the inner bay and small differences result in large \% changes. Of the 4 scenarios considered, placing a single large farm in the inner bay has the least influence on water speeds throughout the bay, causing an $18 \%$ reduction in the inner bay, but almost no change in the mid and outer bay. Placing a single large farm in the middle of the bay causes the greatest reductions in current speeds over the whole $(-19 \%)$, and mid $(-28 \%)$ bay. A farm in the outer bay increases speeds in the inner $(+69 \%)$ and mid bay $(+3 \%)$ while decreasing speeds in the outer bay by $23 \%$. Interestingly, the existing farms cause a greater reduction in current speeds in the inner bay $(-25 \%)$ than any of the other scenarios.

\section{Seston depletion envelopes}

Seston depletion was simulated using a tracer to represent the amount of seston consumed. High tracer concentrations therefore represent high depletion, or low seston concentration. Concentrations were scaled to give values relative to a continuous release of $1 \mathrm{~g}$ $\mathrm{m}^{-3} \mathrm{~h}^{-1}$ of farm volume. Simulations were conducted for the existing farms both including and excluding farm drag, and for the alternative single large farm scenarios including farm drag. The influence of farm drag on seston depletion is illustrated in Fig. 8, which shows the concentrations of a tracer with a decay rate of $k=0.3 \mathrm{~d}^{-1}$ continuously released from the mussel farms in both Port Ligar and Waihinau Bay. Tracer concentration is averaged over a tidal cycle after the total mass of tracer in the system has reached $90 \%$ of steady state (steady state occurs where the addition of tracer equals the rate that tracer decays). The tracer concentration therefore represents the time-averaged concentration, and the spatial distribution is due to the effects of advection and diffusion. Predicted tracer concentrations are shown where farm drag is not included (Fig. 8a), and with drag included at $100 \%$ stocking density (Fig. 8b). The differences in concentrations are shown in Fig. 8c where positive values indicate an increase in concentration due to including farm drag. Tracer concentrations, and therefore potential seston depletion, are higher within farms than in their immediate surrounds. Tracer concentrations are higher in the inner parts of the bays where velocities are lower. Including farm drag increases tracer concentrations in most farms due to the reduction in water speeds and therefore reduced dispersal from advection. However there are 3 farms in inner Port Ligar where tracer concentration is decreased (Fig. 8c) because surrounding farms accelerate flow through these farms. 


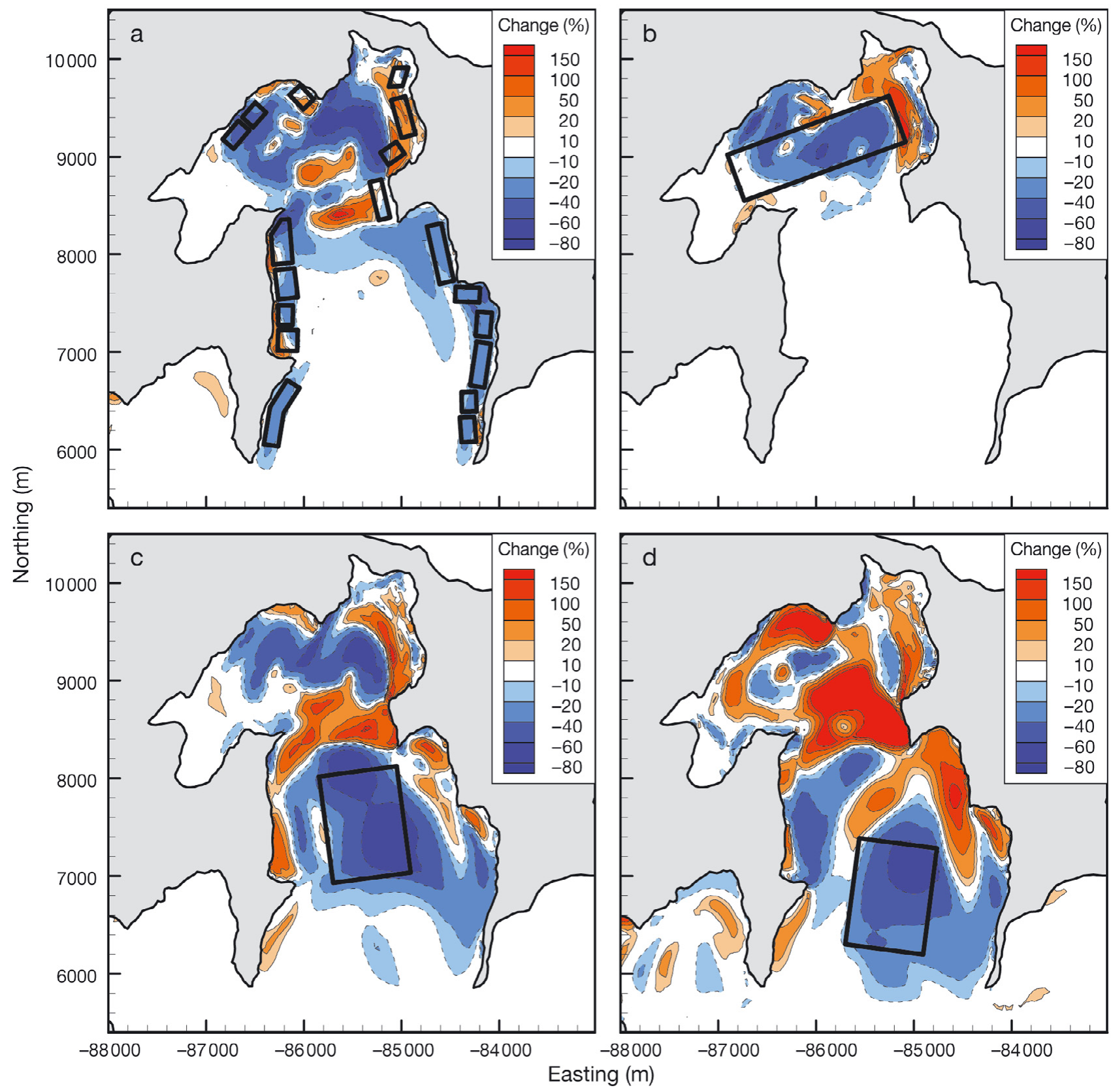

Fig. 7. Comparison of \% change in mean water speed for existing farms in Port Ligar (a), and a single large farm covering the same total area located in the (b) inner bay, (c) mid bay, and (d) outer bay. Positive values (solid contours) indicate an increase in mean water speeds compared to simulations with no farms, negative values (dashed contours) indicate a reduction in speed

The decay rate and dispersion both influence absolute concentrations as well as spatial distributions. If there were no advection or diffusion, then tracer concentration inside farms would reach a steady state value of $S_{\max }=r / k$ where $r$ is the rate of tracer concentration addition within farmed areas $\left(\mathrm{g} \mathrm{m}^{-3} \mathrm{~d}^{-1}\right)$. Concentrations outside farms would be zero. Thus theoretical maximum in-farm tracer concentrations resulting from a tracer release rate of $1 \mathrm{~g} \mathrm{~m}^{-3} \mathrm{~h}^{-1}$ can be pre- dicted as 240,80 and $24 \mathrm{~g} \mathrm{~m}^{-3}$ for $k=0.1,0.3$ and $1.0 \mathrm{~d}^{-1}$ respectively. Slower decay rates and greater tracer release rates result in higher theoretical maximum concentrations. However, simulations were not continued until steady state as this would require very long simulation times. Instead, tracer concentrations were averaged over an M2 tidal cycle $\left(T_{\mathrm{M}_{2}} ; 12.42 \mathrm{~h}\right)$ after the time required to reach $90 \%$ of this theoretical steady state value. The theoretical maximum tracer concen- 
Table 1. Comparison of changes (\%) in mean water speed (M2 tidal component) for marine farm scenarios covering the same total area located in different parts of Port Ligar. Positive values indicate an increase in mean speed, negative values indicate a decrease in mean speed compared to simulations with no marine farms

\begin{tabular}{|lcccc|}
\hline & $\begin{array}{c}\text { Inner } \\
\text { bay }\end{array}$ & $\begin{array}{c}\text { Mid } \\
\text { bay }\end{array}$ & $\begin{array}{c}\text { Outer } \\
\text { bay }\end{array}$ & $\begin{array}{c}\text { Whole } \\
\text { bay }\end{array}$ \\
\hline Existing farms & -25 & -8 & -4 & -6 \\
Single farm inner bay & -18 & -0.5 & 0.0 & -0.7 \\
Single farm mid bay & -12 & -28 & -17 & -19 \\
Single farm outer bay & +69 & +3 & -23 & -14 \\
\hline
\end{tabular}

tration (no advection or diffusion) averaged over this period $\left(S_{\mathrm{m}}\right)$ can be calculated as

$$
S_{\mathrm{m}}=\frac{r}{k}\left[1+\frac{0.1}{k T_{M_{2}}}\left[\exp \left(-k T_{M_{2}}\right)-1\right]\right]
$$

or 216.6, 75.6, and $22.1 \mathrm{~g} \mathrm{~m}^{-3}$ for $k=0.1,0.3$ and $1.0 \mathrm{~d}^{-1}$, respectively.

These values are used to non-dimensionalise tracer concentrations in Fig. 9, which compares the effect of tracer decay rate on the spatial distribution of tracer. The simulations only show tracer released from the farms in Port Ligar, yet the tracer is advected into Waihinau Bay, showing that potential seston depletion may spread beyond individual bays. Seston depletion at a location may result from the combined effect of both nearby and distant farms. At the low decay rate of $k=0.1 \mathrm{~d}^{-1}$ (Fig. 9a), dispersion from advection and dif- fusion distributes tracer over the whole bay, with gradual variations of concentration. Over $65 \%$ of the total tracer mass has been transported out of the bay and peak concentrations are low compared to the theoretical maximum. Non-dimensional concentrations within the farms are $S / S_{\mathrm{m}}=0.15$ to 0.23 in the inner bay, and 0.03 to 0.06 in the mid and outer bay. As the decay rate is increased ( $k=0.3$ and $1.0 \mathrm{~d}^{-1}$ in Fig. 9b,c respectively), dispersion has less effect and in-farm tracer concentrations become closer to the theoretical maximum. Stronger gradients in tracer concentration can be observed, particularly close to farms. At $k=1.0 \mathrm{~d}^{-1}$, tracer concentrations reach $S / S_{\mathrm{m}}=0.63$ in farms in the inner bay, and from 0.15 to 0.40 in the mid and outer bay. Only $27 \%$ of the tracer mass is outside the bay, indicating that far-scale effects are reduced.

Tracer releases are also used to compare the potential effects on seston from a large farm located in the inner, mid or outer bay (Fig. 10). Again, concentrations have been normalised by the theoretical maximum infarm concentrations, and thus are directly comparable to the existing farm scenario shown in Fig. 9b. The risk of seston depletion is greatest for the inner bay farm (Fig. 10a), with peak normalised tracer concentrations of 0.67 . This is greater than the maximum concentration found inside any farm for the existing farm scenario where the peak value was 0.47 . Peak concentrations in the mid and outer bay farm sites are much lower at 0.18 and 0.09 , respectively. The higher velocities through the mid and outer bay farm sites results in much greater dispersion. The amount of tracer carried
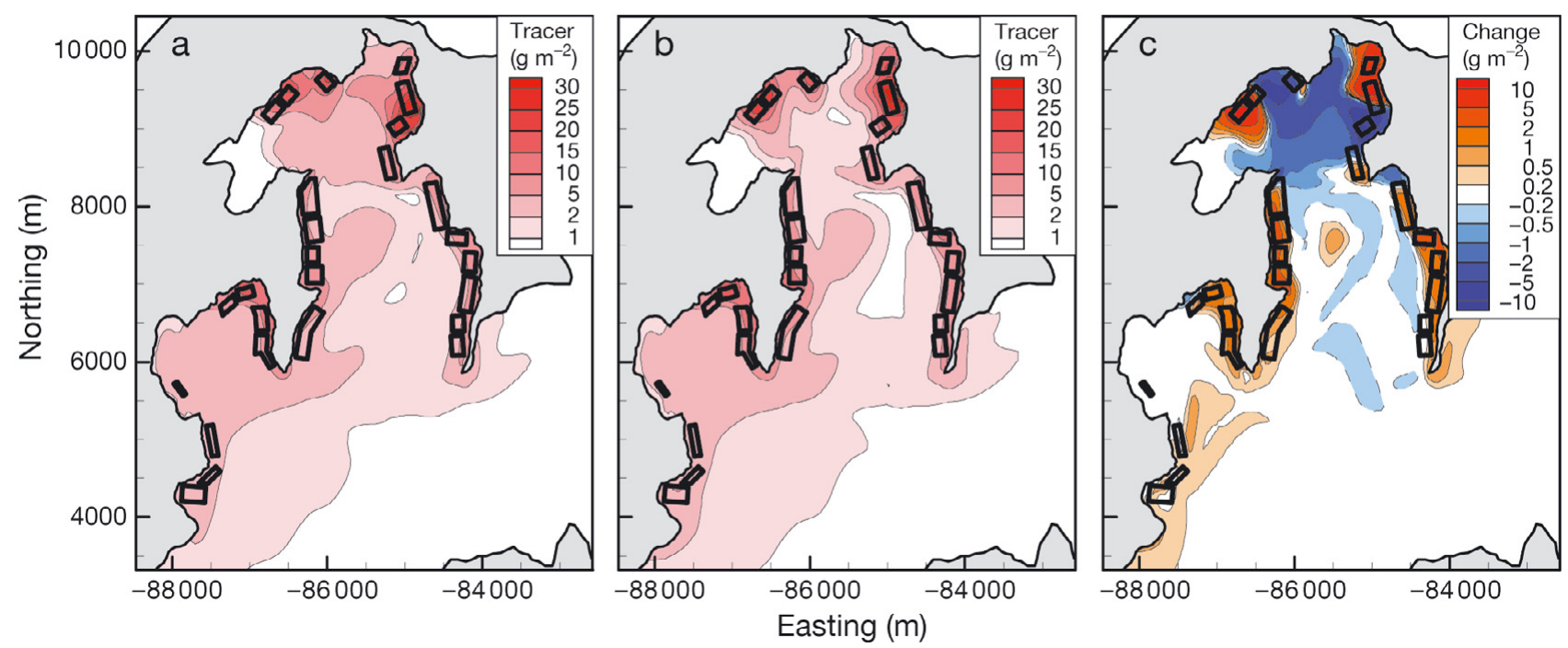

Fig. 8. Comparison of tracer concentrations $\left(\mathrm{g} \mathrm{m}^{-3}\right.$ ) with (a) no farm drag, and (b) farm drag included, and (c) difference in tracer concentrations when farm drag was included, where positive values (solid contours) indicate higher concentrations and negative values (dashed contours) indicate lower concentrations when drag was included. The tracer was released from within all farmed areas (indicated by the black rectangles) at a rate of $1 \mathrm{~g} \mathrm{~m}^{-3} \mathrm{~h}^{-1}$, and has a decay rate of $0.3 \mathrm{~d}^{-1}$. Concentrations are shown averaged over a M2 tidal cycle (12.42 h) after $184.2 \mathrm{~h}$ continuous release. Note that contours are not equally spaced 

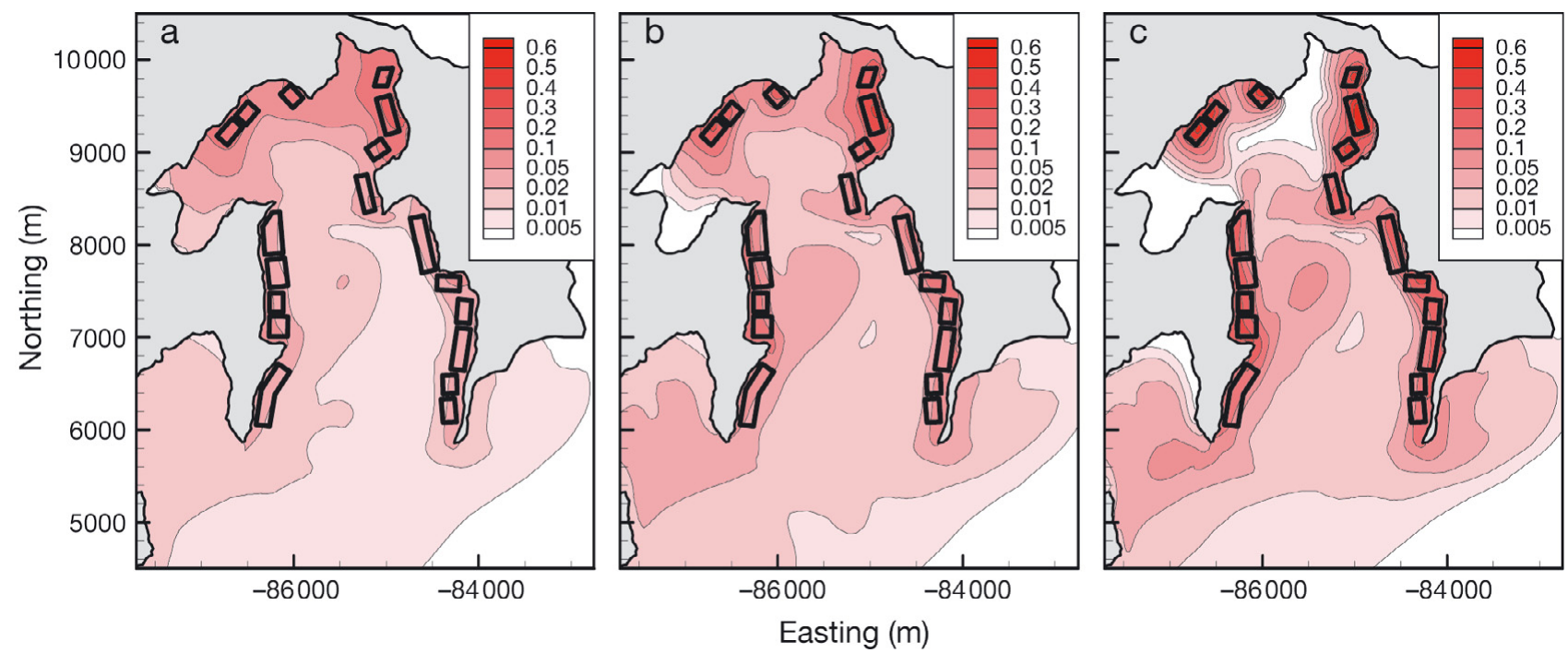

Fig. 9. Comparison of normalised tracer concentration for decay rates of (a) $k=0.1 \mathrm{~d}^{-1}$, (b) $0.3 \mathrm{~d}^{-1}$, and (c) $1.0 \mathrm{~d}^{-1}$. The tracer was released continuously from within existing farm locations (indicated by the black rectangles) at a rate of $1 \mathrm{~g} \mathrm{~m}^{-3} \mathrm{~d}^{-1}$. Concentrations $(S)$ are averaged over a complete M2 tidal cycle $\left(12.42 \mathrm{~h}\right.$ ) after $184.2 \mathrm{~h}$ continuous release, and normalised by $S / S_{m}$, where $S_{m}$ is the maximum concentration that would occur inside a farm in the absence of advection and diffusion
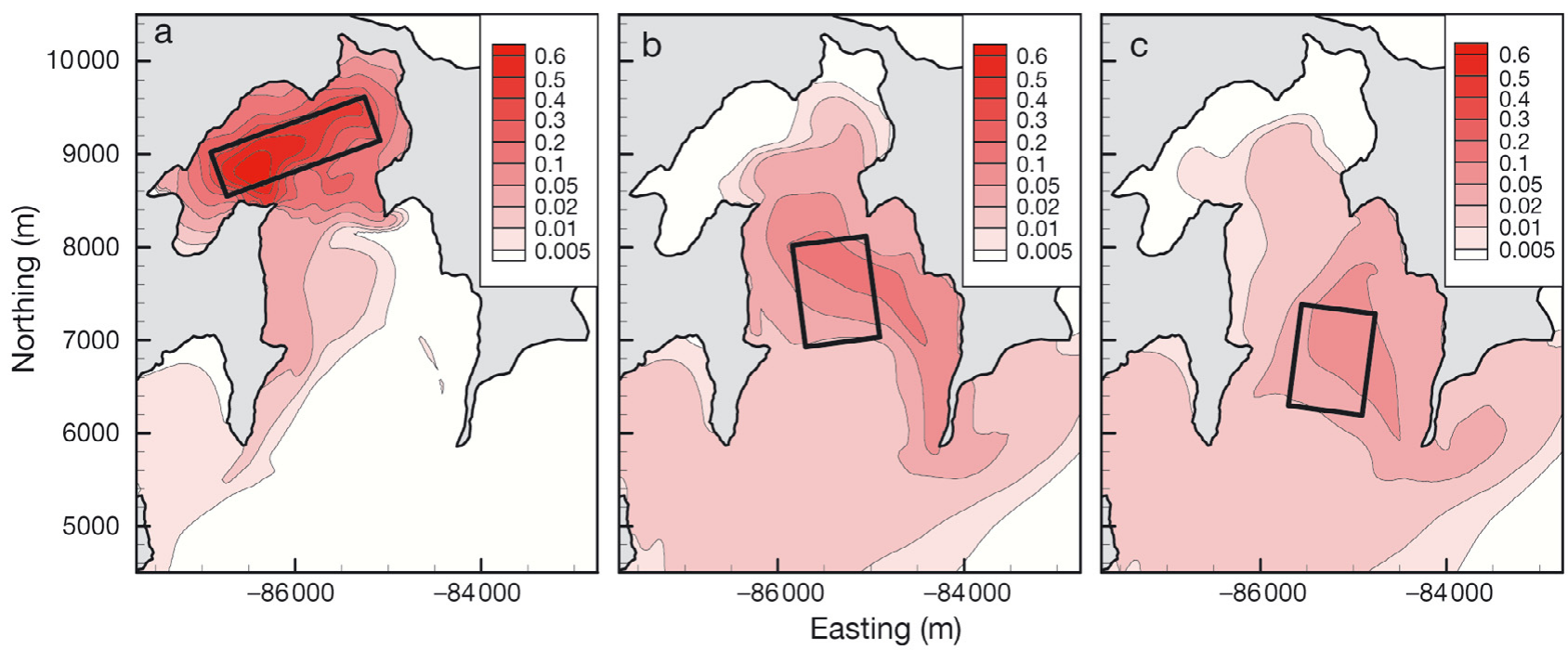

Fig. 10. Comparison of normalised tracer concentration for a continuously release tracer from within a single large farm (indicated by the black rectangles) covering the same total area as all of the existing farms shown in Fig. 9, located in the (a) inner bay, (b) mid bay, and (c) outer bay. The tracer was released at a rate of $1 \mathrm{~g} \mathrm{~m}^{-3} \mathrm{~h}^{-1}$, and has a decay rate of $0.3 \mathrm{~d}^{-1}$. Concentrations $(S)$ are averaged over a complete M2 tidal cycle $(12.42 \mathrm{~h})$ after $184.2 \mathrm{~h}$ continuous release, and normalised by $S / S_{m}$, where $S_{m}$ is the maximum concentration that would occur inside a farm in the absence of advection and diffusion

out of the bay from each of the farms is 7.9, 53 and $68 \%$ for the inner, mid, and outer bay farm sites respectively, compared to $27 \%$ for the existing farms.

The model indicates that time-averaged tracer concentrations outside farm boundaries can be as high as, or in some places higher than, concentrations inside the farm (Fig. 10b,c). Tracer concentrations increase as water passes through the farm, such that the highest concentrations occur where the water has spent the greatest time inside the farm. This is generally on the downstream edge of the farm. The model predicts a persistent clockwise circulation in the outer part of Port Ligar such that regions east of the mid- or outer-bay farm scenarios receive depleted waters over most of the tidal cycle. The time-averaged tracer concentrations are consequently higher than inside parts of the farm where velocities are high and water rapidly exchanged with fluid outside the farm. 


\section{DISCUSSION}

Numerical modelling could be used to assist in choosing suitable locations for shellfish farms, and in determining optimal stocking densities and farm layouts. However, these models must incorporate farm drag. The simulated changes to currents shown here are site specific, yet general effects can be inferred that will be applicable to other locations. The most significant is that the influence of drag from the mussel farms extends beyond the immediate area of the farms. Mussel farms occupied about $10 \%$ of Port Ligar and Waihinau Bay, yet simulations predicted that water speeds were reduced over most of the bays. Furthermore, farms located outside these bays also had an influence on water speeds within the 2 bays. A simulation including all currently existing farms in Pelorus Sound ( 500 farms) reduced water speeds inside Port Ligar by an additional $3 \%$, and indicates that marine farming influences tidal currents over much of Pelorus Sound. Clearly, each marine farm can not be considered in isolation, as each individual farm has a cumulative effect on currents.

Relative reductions in water speed at this study site were greatest in inner Port Ligar, suggesting that the farms acted to reduce the effective width of the bay, enhancing the natural flow constriction caused by the shape of the shoreline. The effect on currents was less in Waihinau Bay, which has a wide aspect ratio. Perimeter farms in long and narrow bays appear to cause a greater constriction to flow than in wider bays. The modelling assumed stocking parameters that are representative of mussels near harvest size. However, to ensure a consistent supply of harvest-sized mussels, farms are seeded at various times throughout the year and a range of mussel sizes are likely to be present. Thus the drag coefficient used in the model may be high, and also may vary between different farms as well as varying over time. The changes in water speeds averaged across the bay are, however, relatively insensitive to the farm drag coefficient (Fig. 6).

The importance of reduction in water speeds caused by marine farms lies in the fact that they affect transport and dispersal of particulate matter and dissolved nutrients. While finfish aquaculture tends to release additional material into the water column - including faecal material, food wastes, particulate and dissolved nutrients - filter feeders such as mussels can reduce the material in suspension. In areas with low ambient seston concentrations, which can occur in New Zealand coastal waters (Hawkins et al. 1999), mussel farms have the potential to further reduce seston concentrations to levels such that mussel growth may be impaired (Hawkins et al. 1999, Strohmeier et al. 2005, Aure et al. 2007). This was taken in consideration by using tracer dispersal simulations with tracer concentrations averaged over a complete M2 tidal cycle in order to obtain an indication of average seston depletion distributions.

A limitation when simulating seston depletion inversely by adding a tracer is that depletion is not limited by ambient seston concentrations. The tracer concentration representing seston depletion could exceed the available seston. However, ambient seston concentrations will fluctuate seasonally and with available nutrient levels, and this complexity is neglected here in the interests of focusing on how the hydrodynamic effects of farms can influence depletion.

The role of stocking density on depletion was not investigated in this study, but its effect may be inferred. Increasing stocking density will have an influence on potential depletion in 2 ways. Firstly, more densely stocked farms have greater drag, resulting in lower current speeds within the farm and thus reducing the replenishment of depleted water in the farm with water from outside. Secondly, more mussels will result in a greater rate of seston consumption, at least until seston is depleted to levels that limit growth. Thus, higher stocking densities are likely to cause greater depletion within and near to farms. The drag-induced reductions in currents will also reduce the dispersal of depleted waters, exacerbating local depletion.

The depletion modelling was simplistic in that no allowance was made for any dependence of feeding rates on concentration (Winter 1973, Riisgard 1991, Riisgard et al. 2003, Maire et al. 2007, Saurel et al. 2007). Plankton regrowth was not modelled directly, but approximated through the use of a growth/decay coefficient. Changing this coefficient shows that where or when seston replenishment rates are low, the absolute depletion will be greater, but the depleted areas will be spread more uniformly. At high regrowth rates, depletion will be both greater in absolute terms, but also confined more locally in and around farmed areas. Coupled biological and hydrodynamic models will improve predictions of mussel growth rates and potential seston depletion.

Seston depletion may not be significant for individual small farms (Pilditch et al. 2001), but large farms or the cumulative effect of several small farms could reduce seston concentrations sufficiently to limit mussel growth. If timescales for regrowth or replenishment are long, then assessments would need to consider large spatial scales - in this example the whole Pelorus Sound system-including the influence of other farms outside the bay or area of interest. Long timescales also increase the need for including non-tidal forcing such as wind, pressure and baroclinity. Mussel growth in Pelorus Sound has 
at times been reduced by food limitation (Hawkins et al. 1999), and this has been linked to large-scale oceanic processes with low oceanic and riverine nutrient inputs to Pelorus Sound during La Niña conditions (Zeldis et al. 2008). The present study illustrates the importance of including farm-induced changes in hydrodynamics in any modelling of physical or biological processes.

Deposition of faecal and pseudo-faecal material, along with shells and detritus shed during farming operations, can build up beneath mussel farms (Stenton-Dozey et al. 2001, Hartstein \& Stevens 2005, Weise et al. 2009). Farm drag could influence deposition patterns by altering currents. Velocities inside the farmed areas, and some distance outside depending on current direction, are reduced which would also reduce horizontal dispersal, increasing accumulation in the vicinity of the farm. However, field and laboratory data (Plew et al. 2006, Plew 2010) show that flow is diverted beneath farms which could increase bed shear stress. In the present study, the analytical model for farm drag predicts that velocities beneath the farm are $1.43 U$, and that the depth-averaged currents inside farmed areas are reduced by $25 \%$ on average in Port Ligar. The ratio of the bed shear stress beneath a farm $\left(\tau_{\mathrm{bf}}\right)$ to the bed shear stress if the farm were not there $\left(\tau_{\mathrm{b} 0}\right)$ is $\tau_{\mathrm{bf}} / \tau_{\mathrm{b} 0}=(1.43 \times 0.75)^{2}=1.15$, or an increase in bed shear stress beneath the farms of $15 \%$. It is possible, therefore, that resuspension is enhanced beneath farms due to underflow, which should be considered in assessments of benthic effects.

The present study also demonstrates how alternative farm locations can be evaluated using numerical modelling. Changing the position of farms can have a significant influence on both currents and potential seston depletion. Through careful positioning and layout, it may be possible to increase current speeds in some areas, which would both enhance food supply and dispersal of depleted waters. This could be one method of enhancing crop growth, and could minimise negative impacts such as deposition beneath farms. In this study, placing a farm in the outer section of Port Ligar increased water speeds in the mid and inner bay, and had the lowest risk of seston depletion, due to the strong currents which flush the farm and the rapid exchange with the main channel outside the bay. Farm shape and aspect ratio were not considered here, but will also influence the likelihood of seston depletion (Pilditch et al. 2001, Aure et al. 2007).

Factors other than productivity or ecological effects influence farm positioning and layout. For example, smaller farms near the coast may be considered to be a smaller navigation hazard (maximum permitted boat speed within $200 \mathrm{~m}$ of shore is 5 knots under New Zealand maritime law) and interfere less with other users of the bay. Other factors include visual impact, wave exposure, recreational or commercial fishing activities; and these will vary between countries or even regions within the same country.

Only tidal currents were considered in the present study. Wind will also drive currents, and the effects of density stratification on circulation were also neglected. Wind-driven circulation and baroclinic forcing may be particularly important in the inner bay where tidal currents are weak. Freshwater inputs from river discharge and rainfall can cause salinity variations along much of Pelorus Sound and induce phase differences in tidal velocities with depth and drive baroclinic currents (Proctor \& Hadfield 1998, Stevens 2003, Stevens 2010). Although water speeds are reduced within farms, the diversion of fluid beneath the canopy may increase bed shear stress (Plew 2010) and enhance re-suspension of material deposited from farms. However, stratification will influence the diversion of flow through and around the farms as well as restrict vertical mixing (Plew et al. 2006). Future modelling efforts should include baroclinic effects, which will require the use of more computationally expensive 3D models.

\section{SUMMARY AND CONCLUSIONS}

Long-line shellfish farms reduce current speeds and this effect extends beyond the boundaries of the farm. Farm-induced changes in currents can occur over bay scales, and may even extend beyond the bay. The collective effect of several small farms can be similar or in some cases greater than that of a single large farm of the same area and stocking density. The potential for farm-induced depletion of seston in low-nutrient environments is greatest where current speeds are low. Farm drag exacerbates potential depletion by increasing residence times within farms, and reducing mean current speeds in bays. It may be possible to enhance flow through or flushing of areas of a bay through position of farms, which could be a method of increasing the carrying capacity of a particular bay. Numerical modelling could be used to aid choosing suitable locations for shellfish farms, and in determining optimal stocking densities and farm layouts. However, models must incorporate farm drag. Because the effects of farm drag are cumulative and can influence neighbouring bays, the modelled area may need to extend beyond the particular site or bay of interest. Future model studies should include non-tidal forcing, extend to 3 dimensions and consider the effects of baroclinity. Coupled ecological-hydrodynamic models will improve predictions of seston depletion and farm productivity. 
Acknowledgements. This project was supported by the New Zealand Foundation for Research, Science and Technology Contracts C01X0507 Sustainable Aquaculture and C01X0513 Complementary Aquaculture. The hydrodynamic model RiCOM was developed by R. Walters. Thanks to J. Dumas for preparation of the model grid, J. Stenton-Dozey and J. Ren for providing access to current meter data; and C. Stevens for comments and suggestions while preparing the manuscript.

\section{LITERATURE CITED}

Aure J, Strohmeier T, Strand O (2007) Modelling current speed and carrying capacity in long-line blue mussel (Mytilus edulis) farms. Aquacult Res 38:304-312

Boyd AJ, Heasman KG (1998) Shellfish mariculture in the benguela system: water flow patterns within a mussel farm in Saldanha Bay, South Africa. J Shellfish Res 17: $25-32$

$>$ Cloern JE, Grenz C, Vidergar-Lucas L (1995) An empirical model of the phytoplankton chlorophyll:carbon ratio- the conversion factor between productivity and growth rate. Limnol Oceanogr 40:1313-1321

Gibbs MM, James MR, Pickmere SE, Woods PH, Shakespeare BS, Hickman RW, Illingworth J (1991) Hydrodynamic and water column properties at six stations associated with mussel farming in pelorus sound, 1984-85. N Z J Mar Freshw Res 25:239-254

- Gillibrand PA, Willis KJ (2007) Dispersal of sea louse larvae from salmon farms: modelling the influence of environmental conditions and larval behaviour. Aquat Biol 1: 63-75

Goldman JC (1986) On phytoplankton growth rates and particulate C:N:P ratios at low light. Limnol Oceanogr 31: 1358-1363

Grant J, Bacher C (2001) A numerical model of flow modification induced by suspended aquaculture in a Chinese bay. Can J Fish Aquat Sci 58:1003-1011

> Hartstein ND, Stevens CL (2005) Deposition beneath longline mussel farms. Aquacult Eng 33:192-213

> Hawkins AJS, James MR, Hickman RW, Hatton S, Weatherhead M (1999) Modelling of suspension-feeding and growth in the green-lipped mussel Perna canaliculus exposed to natural and experimental variations of seston availability in the Marlborough Sounds, New Zealand. Mar Ecol Prog Ser 191:217-232

Heath RA (1985) A review of the physical oceanography of the seas around New Zealand-1982. N Z J Mar Freshw Res 19:79-124

Kiørboe T (1989) Phytoplankton growth rate and nitrogen content: implications for feeding and fecundity in a herbivorous copepod. Mar Ecol Prog Ser 55:229-234

Maire O, Amouroux JM, Duchene JC, Gremare A (2007) Relationship between filtration activity and food availability in the Mediterranean mussel Mytilus galloprovincialis. Mar Biol 152:1293-1307

Okubo A (1971) Oceanic diffusion diagrams. Deep-Sea Res 18:789-802

Pilditch CA, Grant J, Bryan KR (2001) Seston supply to scallops in suspended culture. Can J Fish Aquat Sci 58:241-253

Plew DR (2011) Depth-averaged drag coefficient for modeling flow through suspended canopies. J Hydraul Eng 137: 234-247

> Plew DR, Stevens CL, Spigel RH, Hartstein ND (2005) Hydrodynamic implications of large offshore mussel farms. IEEE J Oceanic Eng 30:95-108

Editorial responsibility: Jonathan Grant,

Halifax, Nova Scotia, Canada
Plew DR, Spigel RH, Stevens CL, Nokes RI, Davidson MJ (2006) Stratified flow interactions with a suspended canopy. Environ Fluid Mech 6:519-539

> Plew DR, Enright MP, Nokes RI, Dumas JK (2009) Effect of mussel bio-pumping on the drag on and flow around a mussel crop rope. Aquacult Eng 40:55-61

> Proctor R, Hadfield M (1998) Numerical investigation into the effect of freshwater inputs on the circulation in Pelorus Sound, New Zealand. N Z J Mar Freshw Res 32:467-482

Riisgard HU (1991) Filtration rate and growth in the blue mussel, Mytilus edulis Linneaus, 1758: dependence on algal concentration. J Shellfish Res 10:29-35

Riisgard HU, Kittner C, Seerup DF (2003) Regulation of opening state and filtration rate in filter-feeding bivalves (Cardium edule, Mytilus edulis, Mya arenaria) in response to low algal concentration. J Exp Mar Biol Ecol 284: $105-127$

Saurel C, Gascoigne JC, Palmer MR, Kaiser MJ (2007) In situ mussel feeding behavior in relation to multiple environmental factors: regulation through food concentration and tidal conditions. Limnol Oceanogr 52:1919-1929

> Stenton-Dozey J, Probyn T, Busby A (2001) Impact of mussel (Mytilus galloprovincialis) raft-culture on benthic macrofauna, in situ oxygen uptake, and nutrient fluxes in Saldanha Bay, South Africa. Can J Fish Aquat Sci 58: 1021-1031

Stevens CL (2003) Turbulence in an estuarine embayment: observations from Beatrix Bay, New Zealand. J Geophys Res 108:3030-3044

Stevens C (2010) Short-term dispersion and turbulence in a complex-shaped estuarine embayment. Cont Shelf Res 30: 393-402

Stevens C, Plew D, Hartstein N, Fredriksson D (2008) The physics of open-water shellfish aquaculture. Aquacult Eng 38:145-160

Strohmeier T, Aure J, Duinker A, Castberg T, Svardal A, Strand O (2005) Flow reduction, seston depletion, meat content and distribution of diarrhetic shellfish toxins in a long-line blue mussel (Mytilus edulis) farm. J Shellfish Res $24: 15-23$

- Walters RA (2005) Coastal ocean models: two useful finite element methods. Cont Shelf Res 25:775-793

- Walters RA, Casulli V (1998) A robust, finite element model for hydrostatic surface water flows. Commun Numer Methods Eng 14:931-940

- Walters RA, Plew DR (2008) Numerical modeling of environmental flows using dam: some preliminary results. Acta Geophysica 56:918-934

Walters RA, Lane EM, Henry RF (2007) Semi-Lagrangian methods for a finite element coastal ocean model. Ocean Model 19:112-124

Walters RA, Gillibrand PA, Bell R, Lane EM (2010) A study of tides and currents in Cook Strait, New Zealand. Ocean Dyn 60:1559-1580

- Weise AM, Cromey CJ, Callier MD, Archambault P, Chamberlain J, McKindsey CW (2009) Shell-fish-depomod: modelling the biodeposition from suspended shellfish aquaculture and assessing benthic effects. Aquaculture 288:239-253

Winter JE (1973) The filtration rate of Mytilus edulis and its dependence on algal coentration, measured by a continuous automatic apparatus. Mar Biol 22:317-328

> Zeldis JR, Howard-Williams C, Carter CM, Schiel DR (2008) ENSO and riverine control of nutrient loading, phytoplankton biomass and mussel aquaculture yield in Pelorus Sound, New Zealand. Mar Ecol Prog Ser 371:131-142 